\title{
Computational modeling of apoptotic signaling pathways induced by cisplatin
}

\author{
Ji-Young Hong ${ }^{1}$, Geun-Hong Kim ${ }^{1 \dagger}$, Jun-Woo Kim ${ }^{1 \dagger}$, Soon-Sung Kwon ${ }^{1}$, Eisuke F Sato ${ }^{2}$, Kwang-Hyun Cho ${ }^{3}$ \\ and Eun Bo Shim ${ }^{1 *}$
}

\begin{abstract}
Background: Apoptosis is an essential property of all higher organisms that involves extremely complex signaling pathways. Mathematical modeling provides a rigorous integrative approach for analyzing and understanding such intricate biological systems.

Results: Here, we constructed a large-scale, literature-based model of apoptosis pathways responding to an external stimulus, cisplatin. Our model includes the key elements of three apoptotic pathways induced by cisplatin: death receptor-mediated, mitochondrial, and endoplasmic reticulum-stress pathways. We showed that cisplatin-induced apoptosis had dose- and time-dependent characteristics, and the level of apoptosis was saturated at higher concentrations of cisplatin. Simulated results demonstrated that the effect of the mitochondrial pathway on apoptosis was the strongest of the three pathways. The cross-talk effect among pathways accounted for approximately $25 \%$ of the total apoptosis level.

Conclusions: Using this model, we revealed a novel mechanism by which cisplatin induces dose-dependent cell death. Our finding that the level of apoptosis was affected by not only cisplatin concentration, but also by cross talk among pathways provides in silico evidence for a functional impact of system-level characteristics of signaling pathways on apoptosis.
\end{abstract}

Keywords: Apoptotic pathways, Cisplatin, Mathematical model

\section{Background}

Cisplatin is an effective chemotherapeutic agent widely used in the treatment of cancer [1,2], but it has several side effects, including dose-dependent renal cell death and nephrotoxicity [3-6]. Uptake of cisplatin occurs mainly through the organic transporter pathway, and the kidney accumulates cisplatin to a greater degree than other organs. These events cause tubular damage and tubular dysfunction [5]. High concentrations of cisplatin lead to necrosis in proximal tubule cells, whereas lower concentrations induce apoptosis [7-10].

Recent studies have indicated that extranuclear events involving mitochondria [11], endoplasmic reticulum (ER) [12], and lysosomes [13] may be important for the

\footnotetext{
* Correspondence: ebshim@kangwon.ac.kr

${ }^{\dagger}$ Equal contributors

'Department of Mechanical and Biomedical Engineering, Kangwon National University, 192-1, Hyoja 2-dong, Chuncheon, Gangwon-do 200-701, Republic of Korea

Full list of author information is available at the end of the article
}

induction of cellular apoptosis by cisplatin [12]. Apoptosis can also be triggered by extracellular death signals, deprivation of survival signals, and genetic damage [14]. Experimental observations [15-22] have shown that apoptosis occurs along three major pathways: i) an extrinsic pathway mediated by death receptors, ii) an intrinsic pathway centered on mitochondria, and iii) an ER-stress pathway (Figure 1A).

Despite numerous experimental studies, the biological mechanism underlying the apoptotic effect of cisplatin is not yet completely understood. In particular, because cellular apoptosis is related to complicated and interactive signaling pathways and also depends on the cisplatin concentration [11], an experimental approach alone may not be cost effective for delineating the complex mechanism of cisplatin-induced apoptosis. Thus, a theoretical approach based on mathematical formulations can provide an alternative to complement experimental methods.

A variety of theoretical studies have investigated the effects of specific pathways or variables related to

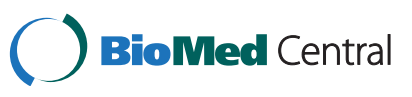



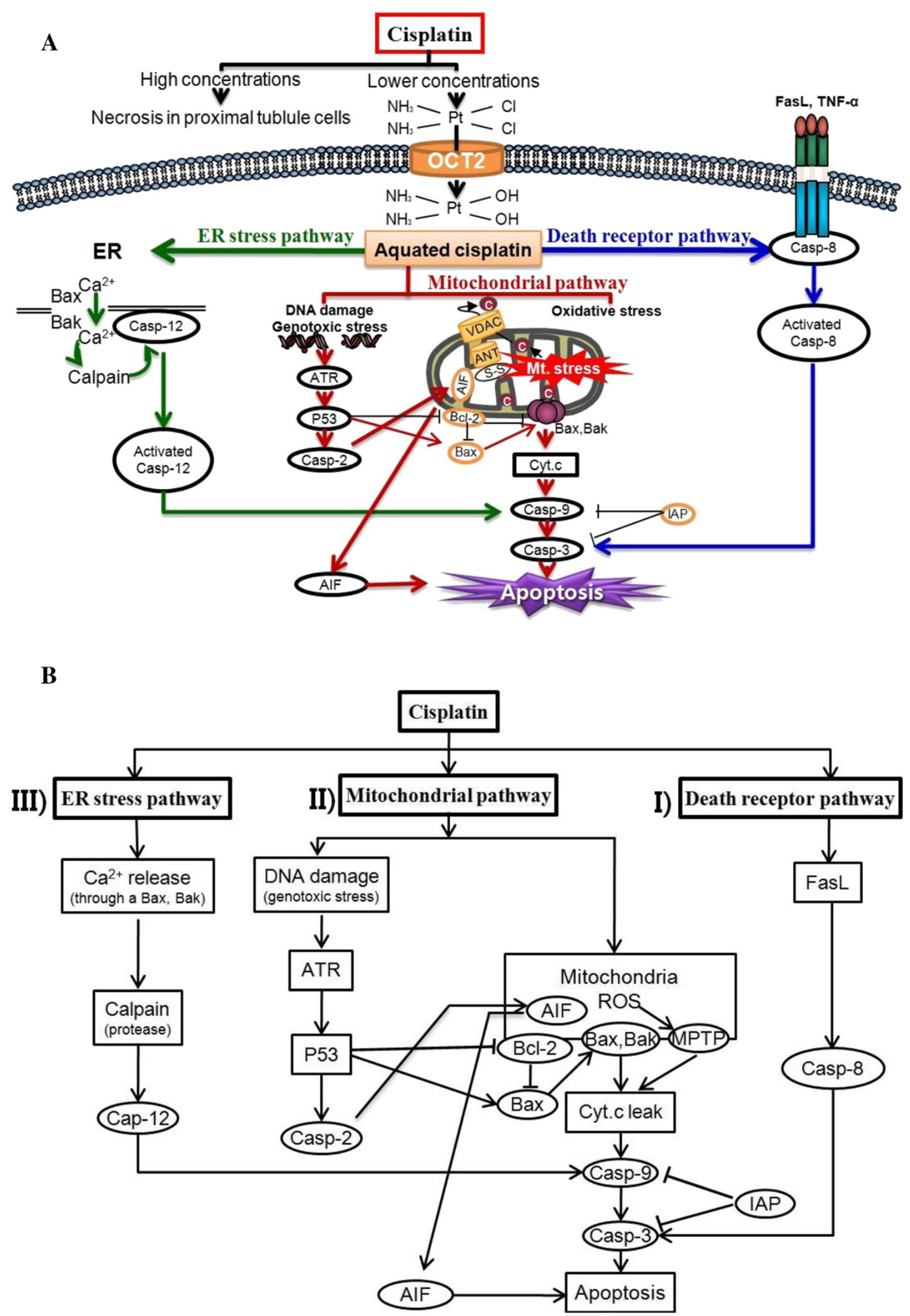

Figure 1 (See legend on next page.) 
(See figure on previous page.)

Figure 1 Mathematical model of the apoptotic pathways induced by cisplatin. (A) Schematic description of the apoptotic pathways induced by cisplatin. (B) Simplified model of apoptotic pathways. Cisplatin activates the three major pathways of apoptosis: i) the extrinsic pathway mediated by death receptors; ii) the intrinsic pathway centered on mitochondria; iii) the endoplasmic reticulum (ER)-stress pathway. Solid arrows denote chemical reactions or upregulation; those terminated by a bar denote inhibition or downregulation.

apoptosis. For example, Fussenegger et al. [23] presented a mechanistic mathematical model describing key elements of receptor-mediated and stress-induced caspase activation. Choi et al. [24] focused on the "slow induction plus fast switching" mechanism of caspase-3 using a simplified model. Apoptosis can also occur in response to activation of the mitochondrial apoptotic pathway [25]. Legewie et al. [26] proposed a mathematical model for the mitochondrial pathway of caspase activation, which is essential for induction of apoptosis by various stimuli, including cytotoxic stress. However, most previous models have focused on partial signaling pathways
A

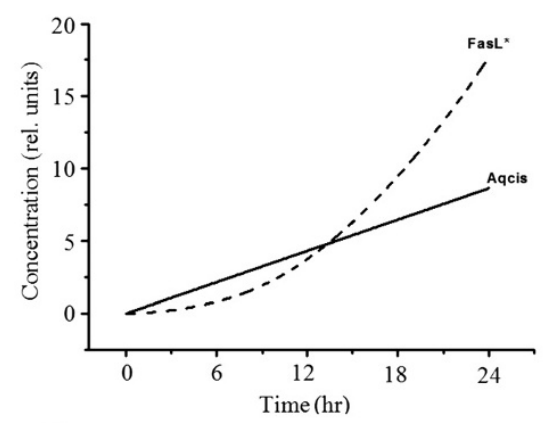

C

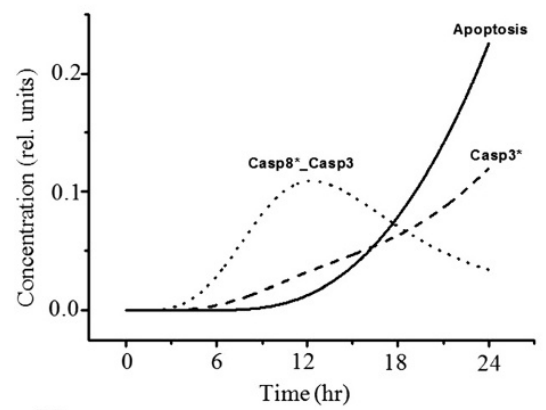

$\mathrm{E}$

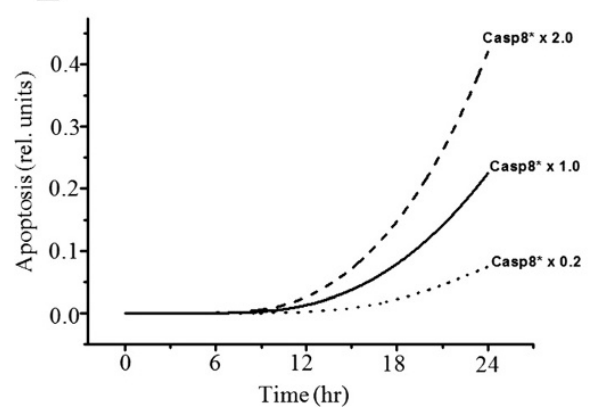

B

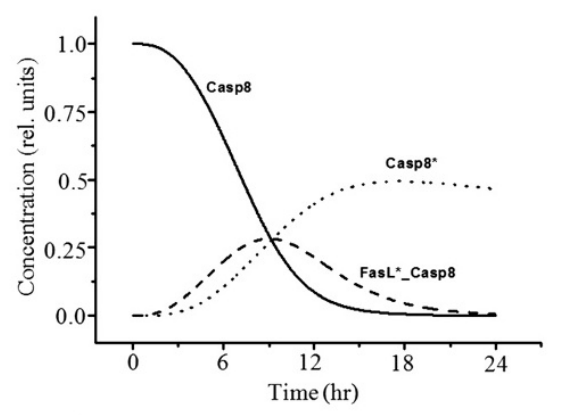

$\mathrm{D}$

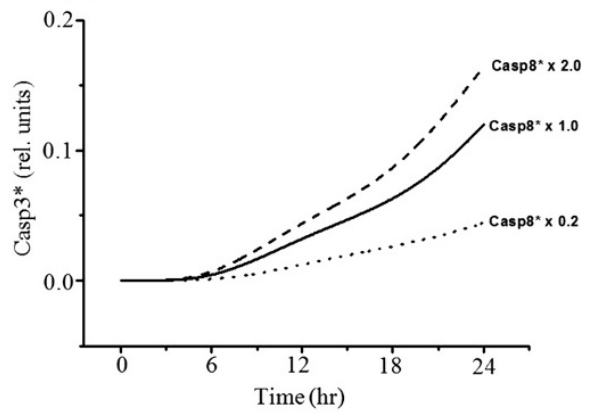

Figure 2 Simulated results of the variables related to the death receptor pathway. (A) Cisplatin becomes aquated and toxic after its entry into cells, thus activating FasL. Aqcis, aquated cisplatin; FasL*, activated FasL. (B) Activated FasL binds caspase-8 and activates the initiator caspase-8. FasL*_Casp8, binding of FasL* and Casp-8; Casp8*, activated caspase-8; Casp8, procaspase-8. (C) The activated caspase-8 leads directly to the activation of downstream caspase-3 and causes apoptosis. Casp8*_casp3, binding of Casp8* and casp3; Casp3*, activated caspase-3. Interaction between activated caspase-8 and caspase-3 activation (D) or apoptosis (E). Casp8* $\times 1.0$, activated caspase-8 at baseline value; Casp $8^{*} \times 2.0$, activated caspase- 8 increase by twofold; Casp $8^{*} \times 0.2$, activated caspase- 8 decrease by fivefold. 
or proteins related to apoptosis, and no theoretical studies have examined an integrative model that includes all three major pathways of apoptotic signaling induced by cisplatin.

In this study, we constructed a large-scale, literaturebased mathematical model to gain a systematic understanding of the biological mechanisms underlying cisplatin-induced apoptosis. Using the model, sequential signaling events, from the uptake of cisplatin to cellular apoptosis, were simulated. We then analyzed the characteristics of dose-dependent cellular apoptosis and crosstalk effects among the three apoptosis pathways through extensive simulations.

\section{Results and discussions}

\section{Model structure}

A schematic representation of the apoptotic signaling network described by our computational model is shown in Figure 1B. The model starts with the uptake of cisplatin into a cell by organic cation transporter 2 (OCT2). After entering the cell, cisplatin is aquated into a highly reactive form that can bind to and induce modification of various molecules [27,28]. Cisplatin activates the three major pathways of apoptosis: i) the extrinsic pathway mediated by death receptors, ii) the intrinsic pathway centered on mitochondria, and iii) the ER stress pathway $[3,4,6,12]$.
A

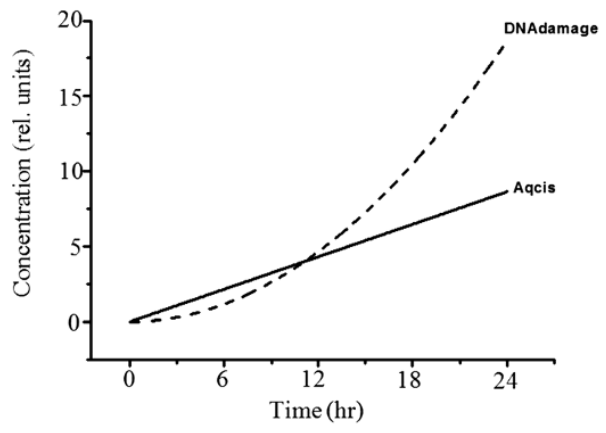

$\mathrm{C}$

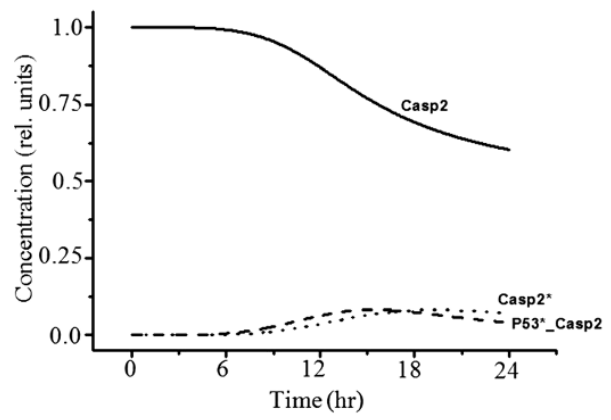

E

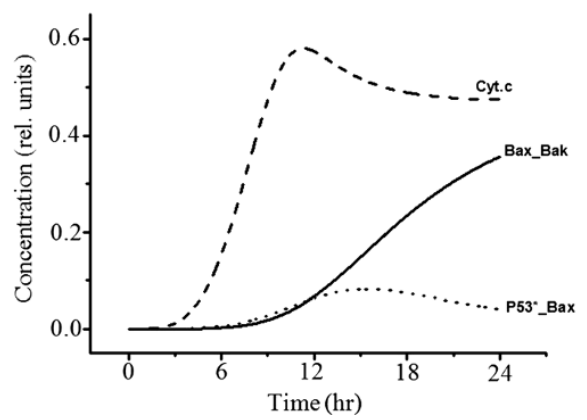

B

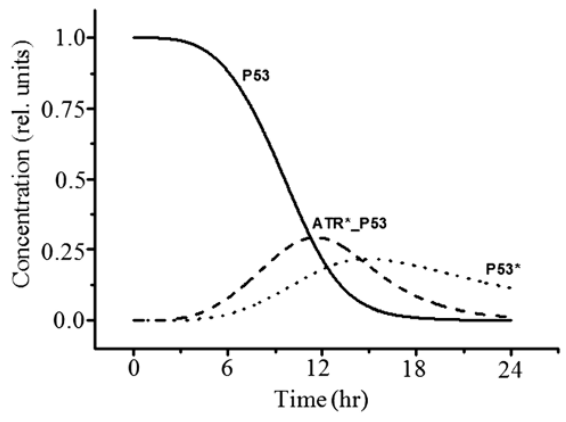

D

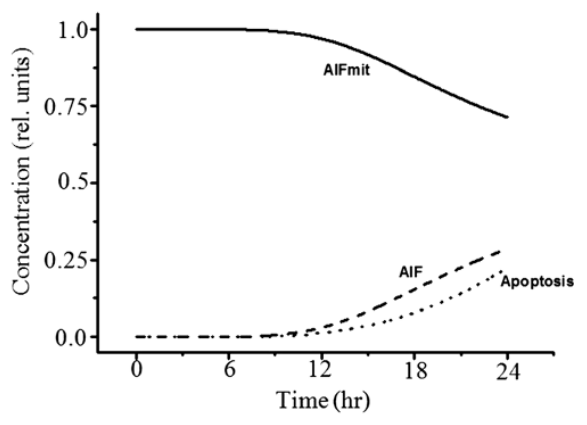

F

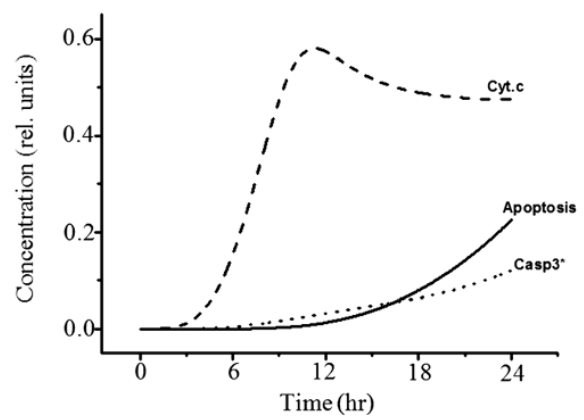

Figure 3 Simulated results of the variables related to the mitochondrial pathway by DNA damage. (A) Cisplatin induces DNA damage. (B) DNA damage activates ATR and p53. ATR _ _p53, binding of ATR* and p53. (C) P53 then induces activation of caspase-2. p53*_Casp2, binding of p53* and casp2, (D) leading to AlF release from mitochondria and subsequent caspase-independent apoptosis. AlFmit, AlF in mitochondria; AIF, leaked AIF in the cytosol. (E, F) On the other hand, apoptosis induced by p53 binding with Bax is dependent on Bax/Bak, which induces cytochrome $\mathrm{c}$ release. Cyt.c, leaked cytochrome $\mathrm{c}$ in the cytosol; p53*_Bax, binding of p53* and Bax; Bax_Bak, binding of Bax and Bak. 
First, in the extrinsic pathway, binding of the death receptors by ligands at the plasma membrane leads to the recruitment and activation of caspase-8, which further activates downstream caspases to induce apoptosis, because the expression levels of FasL, Fas, and tumor necrosis factor-alpha (TNF- $\alpha$ ) increase in response to cisplatin [29-31]. Second, the mitochondrial pathway is the major apoptotic pathway involved in the nephrotoxicity of cisplatin. Cisplatin induces DNA damage, which activates ataxia telangiectasia and Rad-3-related (ATR), resulting in the phosphorylation and activation of p53. Then, p53 activates caspase-2 to elicit apoptosisinducing factor (AIF) release from mitochondria and subsequent caspase-independent apoptosis. The capacity of p53 to directly activate Bax to permeabilize mitochondria permits an uninterrupted pathway leading, e.g., from DNA damage to the mitochondrial release of cytochrome $c$, caspase activation, and apoptosis [3,32-34]. In addition, cisplatin induces mitochondrial dysfunction and increases reactive oxygen species (ROS) production via the disrupted respiratory chain [35]. Oxidative injury of mitochondrial function and mtDNA (mitochondrial DNA) in the kidney are early events elicited by cisplatin [36]. Uncontrollable production of ROS triggers opening of mitochondrial permeability transition pores (MPTP) and induces apoptosis through the release of cytochrome $c$ from mitochondria into the cytosol [37-40]. Third, in the ER stress pathway, increased cytosolic calcium and

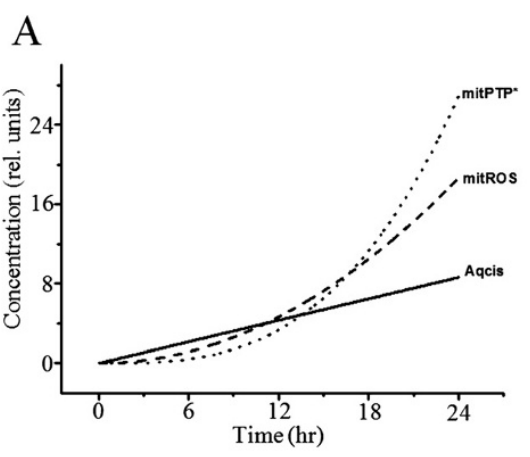

C


E

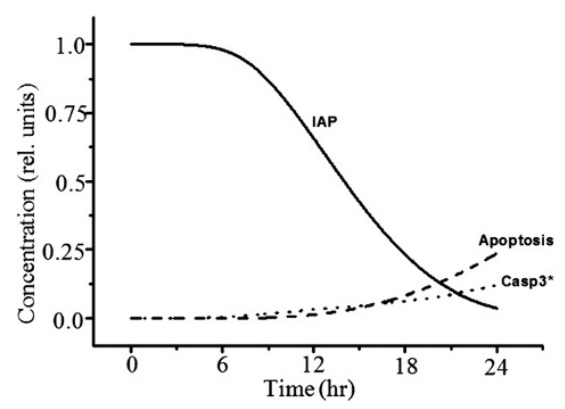

Figure 4 Simulated results of the variables related to the mitochondrial pathway by oxidative stress. (A) Increased ROS in mitochondria by cisplatin induces MPTP. Aqcis, aquated cisplatin; mitROS, increased ROS in mitochondria; mitPTP*, opened mitochondrial permeability transition pore. (B) MPTP induces cytochrome $c$ release, which activates caspase-9. Cyt.c, cytochrome $c$ in cytosol; Cyt. $C_{\text {mit, }}$ Cytochrome $c$ in mitochondria; Cyt.c_Casp9, binding of Cyt.c and Casp9. (C, D) IAP inhibits activated caspase-9 and -3 , which induce apoptosis. Casp9*_IAP, binding of Casp9* and IAP; Casp3*_IAP, binding of Casp3* and IAP; Casp9*_Casp3, binding of Casp9* and Casp3. Activated caspase-9 subsequently initiates caspase-3 activation (D) and induces apoptosis (E). 


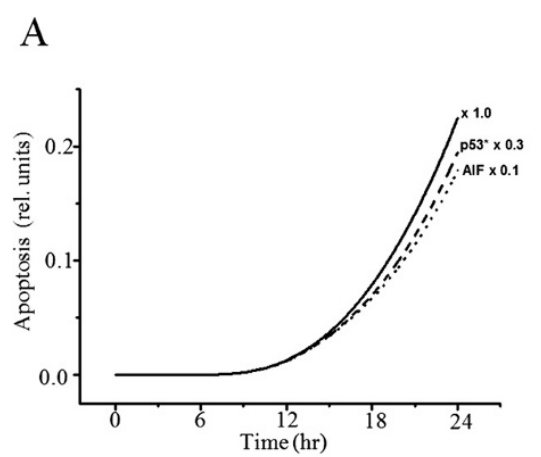

$\mathrm{C}$

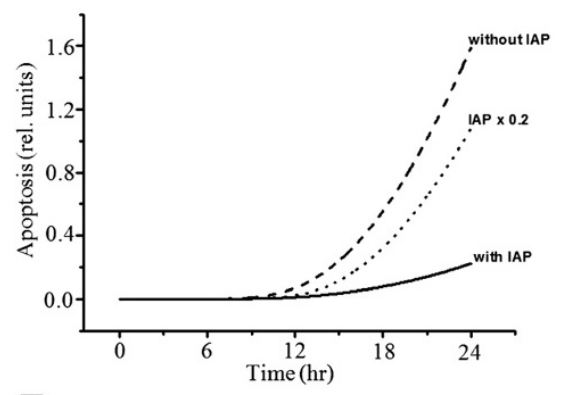

$\mathrm{E}$
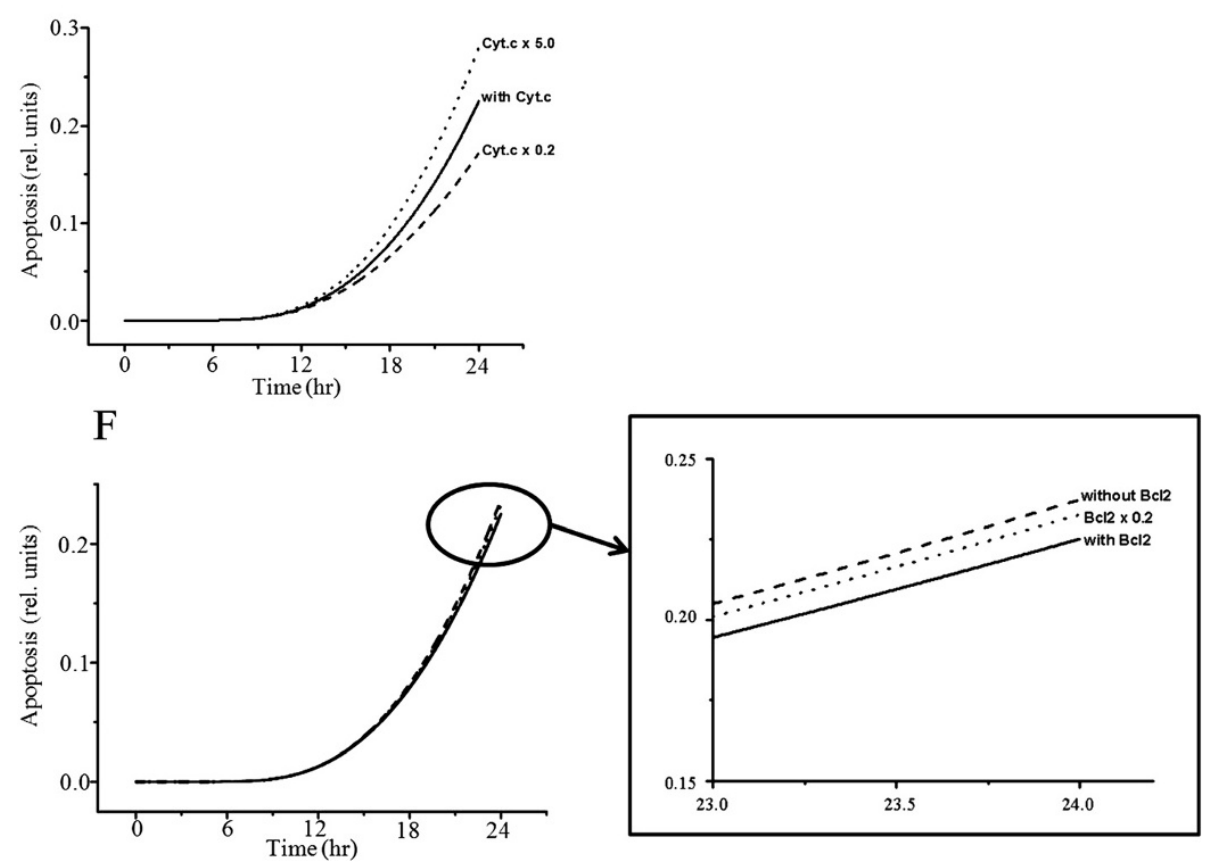

Figure 5 Interaction between apoptosis and AIF, p53 activation, IAP, Bcl-2, or Cyt.c. (A) Interaction between apoptosis and p53* or IAP. Inhibition of p53 and AIF shows a decrease in apoptosis. $\times 1.0$, baseline value; p53* $\times 0.3$, activated p53 decrease by thirtyfold; AIF $\times 0.1$, AlF decrease by tenfold. (B) Interaction between Casp3* and IAP without IAP, IAP $=0$; with IAP, IAP at baseline value; IAP $\times 0.2$, IAP decrease by twentyfold. (C) Interaction between apoptosis and IAP. BCl-2 impairs activation of Bax/Bak. (D) Interaction between Bax_Bak and Bcl-2. Bcl-2 $\times 1.0$, $\mathrm{BCl}-2$ at baseline value; $\mathrm{BCl}-2 \times 0.1, \mathrm{BCl}-2$ decrease by tenfold; $\mathrm{BCl}-2 \times 10.0, \mathrm{BCl}-2$ increase by tenfold. (E) Interaction between apoptosis and Cyt.c. with Cyt.c, Cyt.c at baseline value; Cyt.c $\times$ 5.0, Cyt.c increase by fivefold; Cyt.c $\times 0.2$, Cyt.c decrease by fivefold. (F) Interaction between apoptosis and $\mathrm{BCl}-2$ without $\mathrm{BCl}-2, \mathrm{BCl}-2=0$; with $\mathrm{BCl}-2, \mathrm{BCl}-2$ at baseline value; $\mathrm{BCl}-2 \times 0.2, \mathrm{IAP}$ decrease by twentyfold. 
calpain activation are early events in cisplatin-induced apoptosis [41]. Calpain is a protease responsible for activation of caspase-12 [42], which is localized at the cytosolic face of the ER [43]. Cisplatin induces apoptosis in the absence of DNA damage, and the ER is likely its nonnuclear target [12].

\section{Baseline results of cisplatin-induced apoptosis}

Figure 2 presents time series of the equation variables related to the death receptor pathway. The proteins of the TNF- $\alpha$ receptor family, including Fas ligand (FasL) and TNF receptor 1 (TNFR 1), play important roles in apoptotic cell death. FasL activates the initiator caspase-
8 (Figure 2A, B), and then activated caspase- 8 leads directly to the activation of downstream caspase-3, causing apoptosis (Figure 2C) [29]. Similar to previous experiments of cisplatin-induced cell death [44,45]; all variable curves were plotted until $24 \mathrm{~h}$ after uptake of cisplatin. To evaluate the interaction between activated caspase- 8 and caspase- 3 activation or apoptosis, we tested our mathematical model for different levels of activated caspase- 8 expression. Less-activated caspase- 8 implies reduced caspase- 3 activation and apoptosis (Figure 2D, E). Activated caspase- 8 initiates a caspase cascade by processing the effectors caspase- $3,-6$, and -7 , which in turn cleave many protein substrates. These results showed similar patterns to those reported in the
A

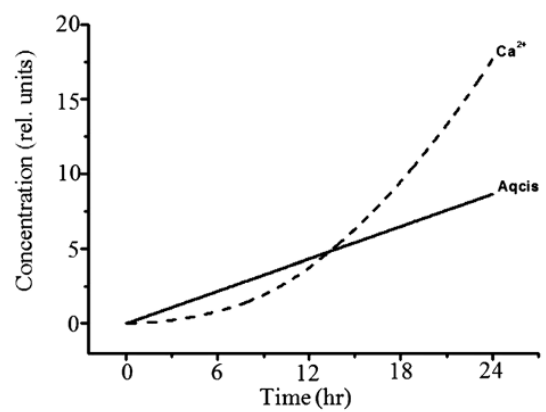

$\mathrm{C}$

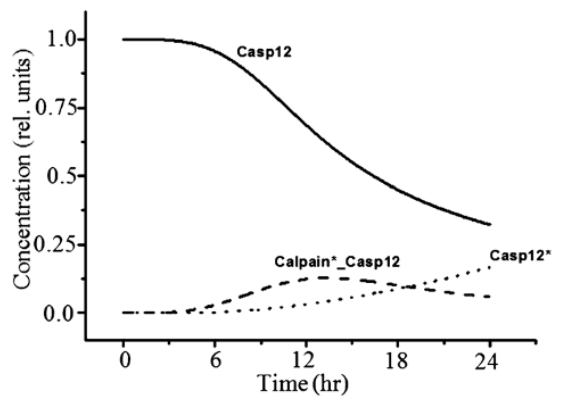

E

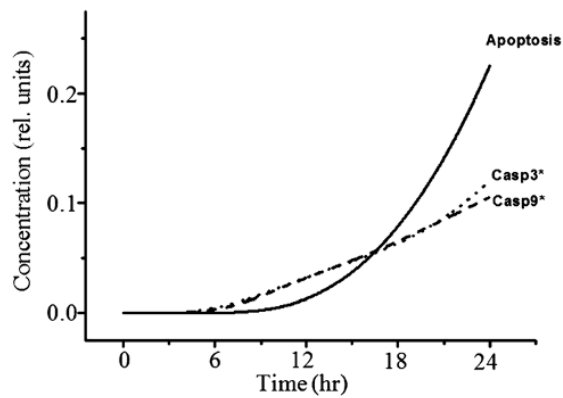

B

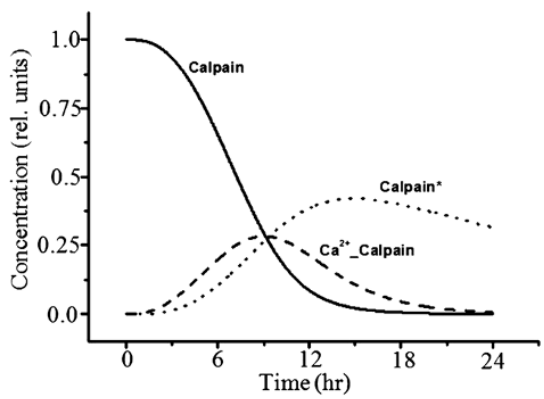

D

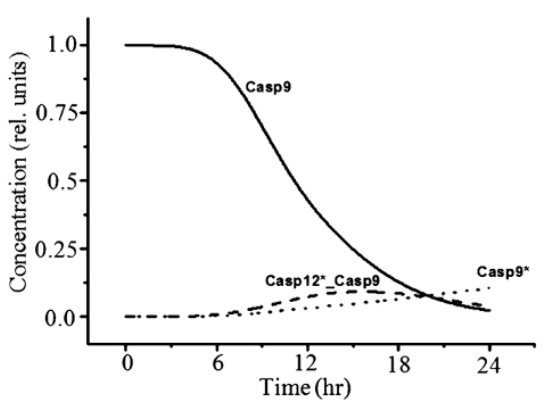

F

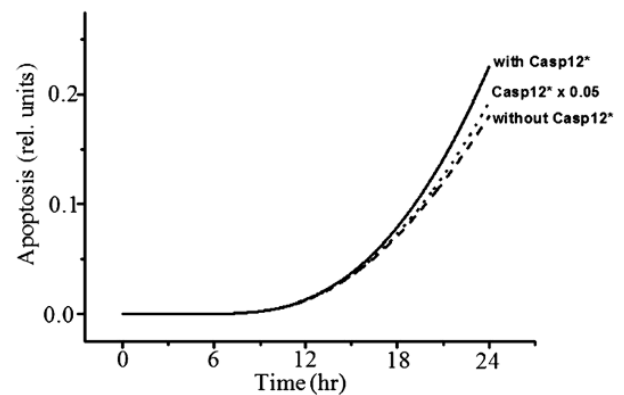

Figure 6 Simulated results of the variables related to the ER-stress pathway. (A) Cisplatin induces ER stress and leads to release of Ca ${ }^{2+}$ from the ER. $\mathrm{Ca}^{2+}$ was leaked from the ER. $\mathrm{Ca}^{2+}$ activates calpain (B), which cleaves procaspase-12 to mature caspase-12 $(\mathbf{C})$. Ca ${ }^{2+}{ }_{-} \mathrm{Calpain}$, binding of $\mathrm{Ca}^{2+}$ and Calpain; Calpain*_Casp12, binding of Calpain* and Casp12. (D) Activated caspase-12 initiates caspase-9. Casp12*_Casp9, binding of Casp12* and Casp9. (E) Activated caspase-9 and -3 cause apoptosis. (F) Interaction between apoptosis and activated caspase-12. The simulation is based on a model with $(\times 1.0)$ or without activated caspase-12. Casp12* $\times 0.05$, Casp $12^{*}$ decrease by twofold. 
A

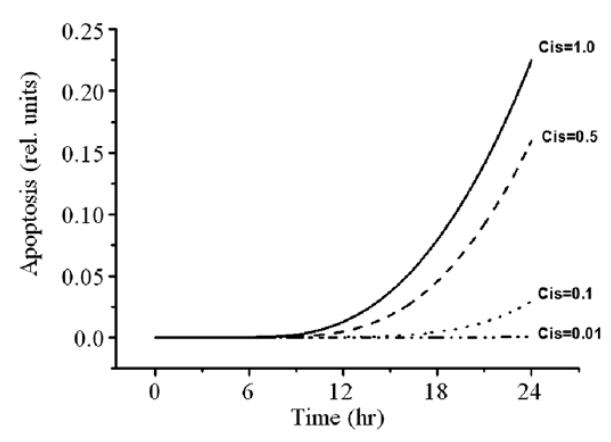

C



$\mathrm{E}$



B

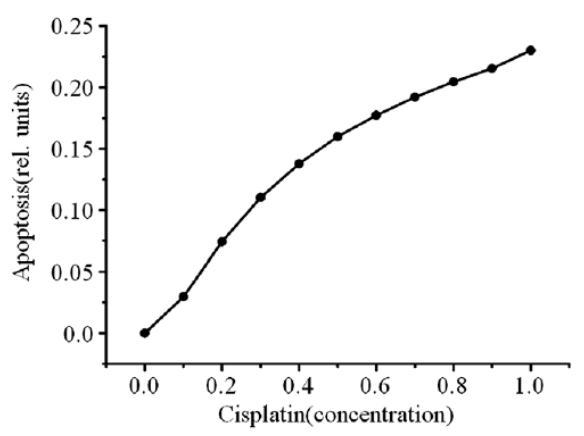

D

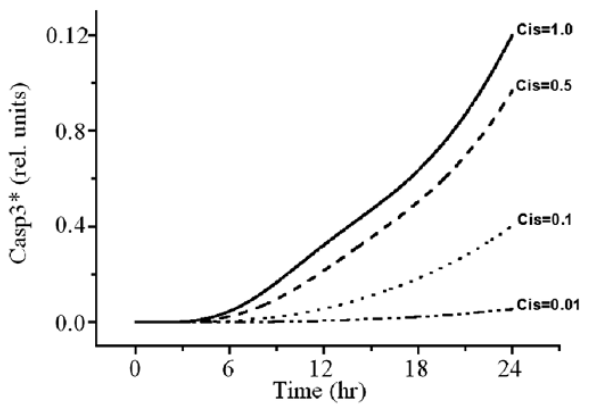

F

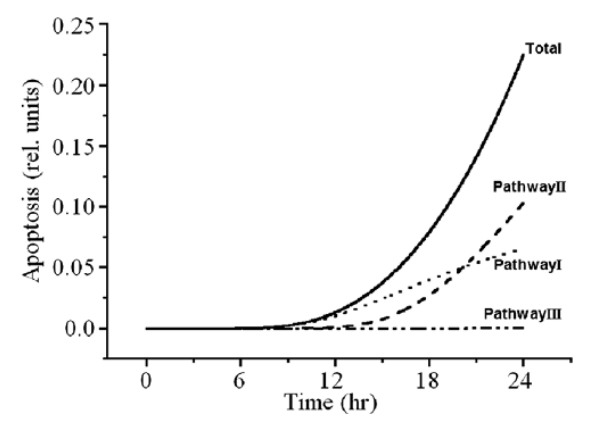

Figure 7 Effect of cisplatin concentration on caspase activity and apoptosis. (A, B) Relationship between apoptosis and various concentrations of cisplatin. Cisplatin induces dose-dependent apoptosis. C, D, and $\mathbf{E}$ show the activation of caspase-8, -3 , and -9 , respectively, with increasing doses of cisplatin for $24 \mathrm{~h}$. (F) Effect of apoptosis by each pathway.

Table 1 Apoptotic variation in response to cisplatin concentration and pathway

\begin{tabular}{ll}
\hline Cisplatin concentration & Apoptosis level \\
\hline 0.0 & 0.0 \\
0.0001 & 0.0 \\
0.001 & $5 \mathrm{E}-6$ \\
0.01 & $4.67 \mathrm{E}-4$ \\
0.1 & $2.96 \mathrm{E}-2$ \\
0.5 & 0.16 \\
1.0 & 0.23 \\
\hline (A) Apoptosis level in various concentrations of cisplatin. (B) Apoptosis level in \\
each pathway.
\end{tabular}

literature [29], indicating that caspase- 8 is a major initiator caspase in death receptor signaling.

Time-dependent curves of the variables related to the mitochondrial pathway of apoptosis due to mtDNA damage and oxidative stress are plotted in Figures 3

\section{Table 2 Apoptosis level in each pathway}

\begin{tabular}{ll}
\hline Pathway & Apoptosis level \\
\hline Total & $0.22512(100 \%)$ \\
Pathway I & $0.065424(29.1 \%)$ \\
Pathway II & $0.103267(45.9 \%)$ \\
Pathway III & $1.83 \mathrm{E}-4(0.08 \%)$ \\
Cross talk effect & $0.0561(24.9 \%)$ \\
\hline
\end{tabular}


which triggers caspase-3 (Figure 4D) and causes consequent apoptosis (Figure 4E).

When we inhibited p53 or AIF, the simulated graphs showed similar patterns to previously reported experimental results [32]: inhibition of p53 or AIF provides protection against cisplatin-induced apoptosis (Figure 5A). Reduced inhibitor of apoptosis protein (IAP) increases the concentration of activated caspase-3, increasing the probability of apoptosis (Figure $5 \mathrm{~B}, \mathrm{C}$ ). The anti-apoptotic protein Bcl-2 impairs the activation of Bax/Bak (Figure 5D), thereby maintaining mitochondrial membrane integrity and reducing cytochrome $c$ leakage, which results in a decrease in the probability of apoptosis (Figure 5E). However, a reduction in Bcl-2 expression slightly increases the probability of apoptosis (Figure 5F).

Accumulation of excessive proteins or disruption of calcium homeostasis in the ER can cause apoptosis due to ER stress $[42,52]$. Transient curves of the variables related to the ER-stress pathway are presented in Figure 6. ER stress causes conformational changes and/or oligomerization of pro-apoptotic Bak and Bax at the ER membrane [53], leading to release of $\mathrm{Ca}^{2+}$ from the ER (Figure 6A). $\mathrm{Ca}^{2+}$ then activates calpain in the cytosol, which cleaves procaspase-12 to mature caspase- 12 in the ER (Figure 6B, C) [54]. Activated caspase-12 then initiates a caspase cascade through cleavage of procaspase- 9 and thus causes apoptosis (Figure 6D, E) [55]. Inhibition of caspase-12 activated by cisplatin induces a slight decrease in the probability of apoptosis (Figure 6F). These results suggest that ER stress and consequent activation of caspase- 12 play a role in cisplatin-induced nephrotoxicity, but their effect on apoptosis was not remarkable.

\section{Simulation of dose-dependent cell death caused by cisplatin}

Cisplatin has been shown to induce time- and dosedependent cell death [56,57]. Although the maximum concentration of cisplatin was set to 1 in our model, we simulated the apoptosis level in response to various concentrations of cisplatin on a timescale. The increase in the level of apoptosis was dependent on the concentration of cisplatin (Figure 7A, B, Table 1). Cisplatin-

Table 4 Ordinary differential equation

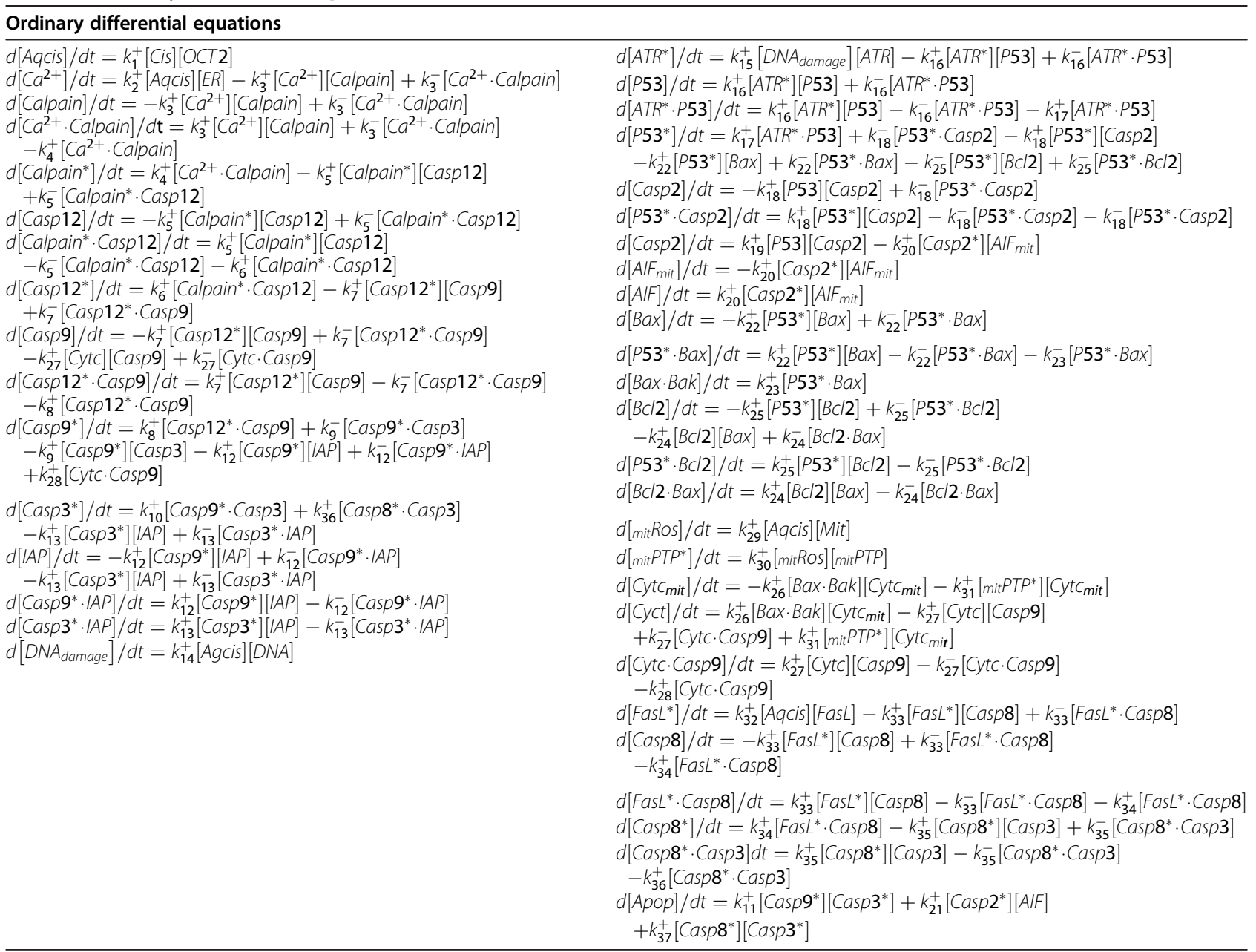


induced apoptosis was further confirmed by the activities of caspase-9, -8 , and -3 (Figure 2C, $\mathrm{E}$ and Figure $6 \mathrm{E}$ ). Figure $7 \mathrm{C}-\mathrm{E}$ indicates that increasing doses of cisplatin can cause significant activation of caspase-8, -3, and -9 . Although the level of apoptosis increased linearly at lower concentrations of cisplatin, it exhibited a nearly saturated curve at higher concentrations (Figure 7B). A previous experimental study [55] also observed a saturated probability of apoptosis beyond a threshold concentration of cisplatin.

\section{Analysis of cross-talk effects of apoptotic signaling pathways}

To evaluate the relative contribution of each signaling pathway to apoptosis, we first simulated three test cases in which only one pathway among the three was activated, with the other two pathways fully inactivated (Figure 7F, Table 2). According to the results, the mitochondrial pathway made the greatest contribution to the level of apoptosis (46\%), whereas the contribution of the ER stress pathway $(0.08 \%)$ was negligible. The contribution of the death-receptor pathway was about $29 \%$. The sum of the contributions of the three pathways was about $75 \%$ and lower than that of the whole model including all three pathways (Table 2). Thus, we hypothesize that cross talk among pathways accounts for $25 \%$ of the

Table 5 Parameter values adopted in the model

\begin{tabular}{|c|c|c|c|c|c|c|c|}
\hline \multicolumn{8}{|c|}{ Reaction rate constants } \\
\hline $\mathrm{k}_{1}^{+}$ & $1 \mu \mathrm{M}^{-1} \mathrm{~s}^{-1}$ & & & $\mathrm{k}_{20}^{+}$ & $1 \mu \mathrm{M}^{-1} \mathrm{~s}^{-1}$ & & \\
\hline $\mathrm{k}_{2}^{+}$ & $0.5 \mu \mathrm{M}^{-1} \mathrm{~s}^{-1}$ & & & $\mathrm{k}_{21}^{+}$ & $1 \mu \mathrm{M}^{-1} \mathrm{~s}^{-1}$ & & \\
\hline $\mathrm{k}_{3}^{+}$ & $1 \mu M^{-1} s^{-1}$ & $\mathrm{k}_{3}^{-}$ & $1 \mathrm{~s}^{-1}$ & $\mathrm{k}_{22}^{+}$ & $1 \mu \mathrm{M}^{-1} \mathrm{~s}^{-1}$ & $k_{22}$ & $1 \mathrm{~s}^{-1}$ \\
\hline $\mathrm{k}_{4}^{+}$ & $1 \mathrm{~s}^{-1}$ & & & $\mathrm{k}_{23}^{+}$ & $1 \mathrm{~s}^{-1}$ & & \\
\hline $\mathrm{k}_{5}^{+}$ & $1 \mu M^{-1} s^{-1}$ & $k_{5}^{-}$ & $1 \mathrm{~s}^{-1}$ & $\mathrm{k}_{24}^{+}$ & $1 \mu \mathrm{M}^{-1} \mathrm{~s}^{-1}$ & $k_{24}$ & $1 \mathrm{~s}^{-1}$ \\
\hline $\mathrm{k}_{6}^{+}$ & $1 \mathrm{~s}^{-1}$ & & & $k_{25}^{+}$ & $1 \mu M^{-1} s^{-1}$ & $k_{25}$ & $1 \mathrm{~s}^{-1}$ \\
\hline $\mathrm{k}_{7}^{+}$ & $10 \mu \mathrm{M}^{-1} \mathrm{~s}^{-1}$ & $\mathrm{k}_{7}^{-}$ & $0.5 \mathrm{~s}^{-1}$ & $\mathrm{k}_{26}^{++}$ & $10 \mu \mathrm{M}^{-1} \mathrm{~s}^{-1}$ & & \\
\hline $\mathrm{k}_{8}^{+}$ & $1 \mathrm{~s}^{-1}$ & & & $\mathrm{k}_{27}^{+}$ & $1 \mu M^{-1} s^{-1}$ & $k_{27}$ & $1 s^{-1}$ \\
\hline $\mathrm{kg}_{9}^{++}$ & $10 \mu \mathrm{M}^{-1} \mathrm{~s}^{-1}$ & $\mathrm{~K}_{9}^{-\dagger}$ & $0.5 s^{-1}$ & $k_{28}^{+}$ & $1 \mathrm{~s}^{-1}$ & & \\
\hline $\mathrm{k}_{10}^{++}$ & $0.1 \mathrm{~s}^{-1}$ & & & $\mathrm{k}_{29}^{+}$ & $0.5 \mu \mathrm{M}^{-1} \mathrm{~s}^{-1}$ & & \\
\hline $\mathrm{k}_{11}^{+}$ & $1 \mu M^{-1} s^{-1}$ & & & $\mathrm{k}_{30}^{+}$ & $0.5 \mu M^{-1} s^{-1}$ & & \\
\hline $\mathrm{k}_{12}^{+\dagger}$ & $5 \mu M^{-1} s^{-1}$ & $\mathrm{~K}_{12}^{-\dagger}$ & $0.0035 s^{-1}$ & $k_{31}^{+}$ & $1 \mu \mathrm{M}^{-1} \mathrm{~s}^{-1}$ & & \\
\hline $\mathrm{k}_{13}^{++}$ & $5 \mu M^{-1} s^{-1}$ & $\mathrm{~K}_{13}^{-\dagger}$ & $0.0035 s^{-1}$ & $k_{32}^{+}$ & $0.5 \mu M^{-1} s^{-1}$ & & \\
\hline $\mathrm{k}_{14}^{+}$ & $0.5 \mu \mathrm{M}^{-1} \mathrm{~s}^{-1}$ & & & $\mathrm{k}_{33}^{+}$ & $1 \mu \mathrm{M}^{-1} \mathrm{~s}^{-1}$ & $k_{33}$ & $1 \mathrm{~s}^{-1}$ \\
\hline$k_{15}^{+}$ & $0.5 \mu M^{-1} s^{-1}$ & & & $\mathrm{k}_{34}^{+}$ & $1 \mathrm{~s}^{-1}$ & & \\
\hline $\mathrm{k}_{16}^{+}$ & $1 \mu M^{-1} s^{-1}$ & $k_{16}$ & $1 \mathrm{~s}^{-1}$ & $k_{35}^{+}$ & $1 \mu \mathrm{M}^{-1} \mathrm{~s}^{-1}$ & $k_{35}=$ & $1 \mathrm{~s}^{-1}$ \\
\hline $\mathrm{k}_{17}^{+}$ & $1 \mathrm{~s}^{-1}$ & & & $\mathrm{k}_{36}^{+}$ & $1 \mathrm{~s}^{-1}$ & & \\
\hline $\mathrm{k}_{18}^{+}$ & $1 \mu \mathrm{M}^{-1} \mathrm{~s}^{-1}$ & $\mathrm{k}_{18}^{-}$ & $1 \mathrm{~s}^{-1}$ & $\mathrm{k}_{37}^{+}$ & $1 \mu \mathrm{M}^{-1} \mathrm{~s}^{-1}$ & & \\
\hline $\mathrm{k}_{19}^{+}$ & $1 \mathrm{~s}^{-1}$ & & & & & & \\
\hline
\end{tabular}

$\mathbf{t}$, cited parameters [44]. Unit of reaction rate constant: $\mathrm{M}^{-1} \mathrm{~s}^{-1}$ for bimolecular reactions, $\mathrm{s}^{-1}$ for monomolecular reactions [44].
Table 6 All values are in arbitrary units

\begin{tabular}{|c|c|c|c|}
\hline Initial conditions & & & \\
\hline$\overline{\mathrm{OCT} 2}$ & 1 & Apoptosis & $\overline{0}$ \\
\hline ER & 1 & Aqcis & 0 \\
\hline Calpain & 1 & Calpain* & 0 \\
\hline Caspase-12 & 1 & Caspase- $12^{*}$ & 0 \\
\hline Caspase-9 & 1 & Caspase- $9^{*}$ & 0 \\
\hline Caspase-3 & 1 & Caspase- $3^{*}$ & 0 \\
\hline IAP & 1 & Caspase-9*.|AP & 0 \\
\hline DNA & 1 & DNA damage & 0 \\
\hline ATR & 1 & ATR* $^{*}$ & 0 \\
\hline p53 & 1 & $\mathrm{p} 53^{*}$ & 0 \\
\hline AlFmit & 1 & AlF & 0 \\
\hline Bax & 1 & Bax.Bak & 0 \\
\hline $\mathrm{BCl}-2$ & 1 & $\mathrm{p} 53^{*} \cdot \mathrm{BCl}-2$ & 0 \\
\hline Mit & 1 & Cyt.c.Caspase-9 & 0 \\
\hline mitPTP & 1 & mitPTP* & 0 \\
\hline Cyt. $C_{\text {mit }}$ & 1 & Cyt.c & 0 \\
\hline Caspase-8 & 1 & Caspase- $8^{*}$ & 0 \\
\hline FasL & 1 & FasL* & 0 \\
\hline Caspase-2 & 1 & Caspase- $2^{*}$ & 0 \\
\hline $\mathrm{Ca}^{2+}$ & 0 & Caspase- $8^{*}$.Caspase- 3 & 0 \\
\hline $\mathrm{Ca}^{2+} \cdot$ Calpain & 0 & FasL*.Caspase-8 & 0 \\
\hline Calpain*.Caspase-12 & 0 & ATR*.p53 & 0 \\
\hline mitRos & 0 & Caspase- $3^{*} \cdot \mid$ AP & 0 \\
\hline Caspase- $12^{*}$.Caspase- 9 & 0 & Caspase- $9^{*}$.Caspase- 3 & 0 \\
\hline p53*.Caspase- 2 & 0 & $\mathrm{p} 53^{*} \cdot \mathrm{Bax}$ & 0 \\
\hline $\mathrm{Bcl}-2 \cdot \mathrm{Bax}$ & 0 & & \\
\hline
\end{tabular}

*, activated components.

contribution to the level of apoptosis. This cross-talk portion includes the effects of three possible interactions: i) between death receptor and ER-stress pathways, ii) between death receptor and mitochondrial pathways, and iii) between ER-stress and mitochondrial pathways.

Despite substantial progress in understanding the biological mechanisms of cisplatin-induced apoptosis, several questions remain. In particular, complicated molecular interactions, such as cross talk among apoptotic pathways, are not fully understood. In this study, we provided a mechanism-based mathematical model to gain a comprehensive system-level understanding of apoptosis induced by cisplatin. Because our model simulation can be costeffectively repeated for many different sets of conditions, it provides a useful method for examining complex system behavior and for guiding experimental design.

Although many mathematical models have analyzed apoptosis, they have been limited to partial signaling pathways or to proteins related to apoptosis. No theoretical studies have proposed an integrative model that includes 


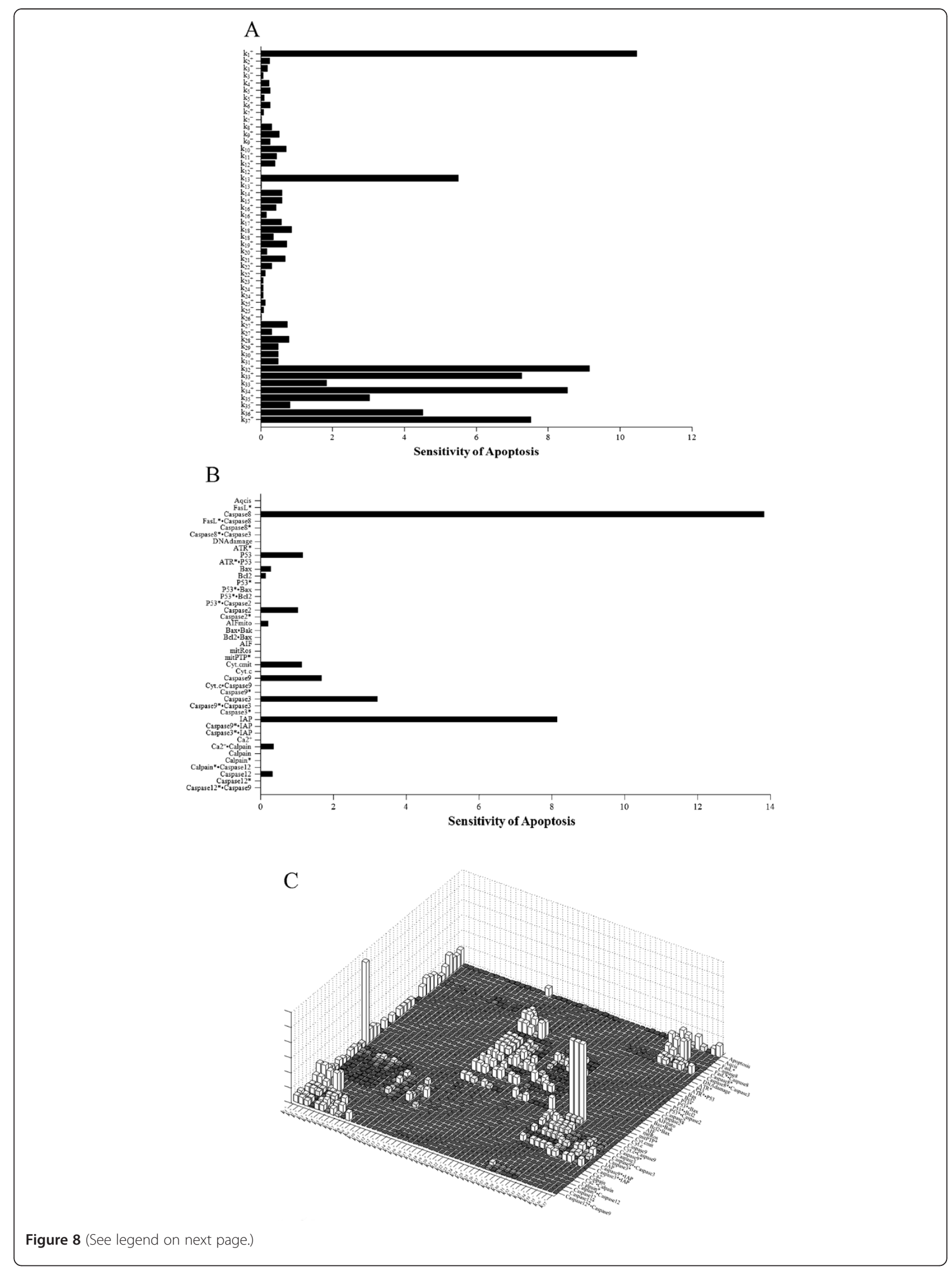


(See figure on previous page.)

Figure 8 Sensitivity analyses of rate constants and initial conditions for the entire model. (A) Sensitivity of each rate constant for apoptosis. (B) Sensitivity of each initial condition for apoptosis. (C) Sensitivity of each rate constant for whole components.

all three major pathways of apoptotic signaling induced by cisplatin. Therefore, we aimed to systematically analyze sequential molecular events of the apoptotic signaling process, from the uptake of cisplatin to cross-talk effects among pathways and ultimately to apoptosis.

We first conducted baseline simulations of cisplatininduced apoptosis and compared the results to previous studies. Our simulations reproduced similar patterns to experimental data and available information from the literature (Figure 2A-C, Figure 3, Figure 4, and Figure 6A-E). We then conducted parametric studies to delineate the effects of critical signaling molecules on apoptosis. To evaluate the role of caspase- 8 as a major initiator of death receptor signaling, we simulated variation in activated caspase- 3 and the level of apoptosis based on the level of activated capase-8 (Figure 2D, E), demonstrating a remarkable increase in the level of apoptosis at higher concentrations of activated capase-8. In the mitochondrial pathway of apoptosis, inhibition of p53 or the level of AIF decreased apoptosis (Figure 5A).

We also showed that cisplatin induces dose-dependent characteristics of apoptosis (Figure 7A, B, Table 1), but the apoptosis level was saturated at higher concentrations of cisplatin, similar to a previous experiment [57]. Apoptosis with respect to cisplatin concentration was also affected by cross talk among pathways (Figure 5 and Figure 7). To evaluate the contribution of each pathway to apoptosis, we used a simulation protocol in which only one pathway was activated while the other two pathways were inactivated. According to the results, the effect of the mitochondrial signaling pathway on apoptosis was largest (46\%), whereas the effect of the ER-stress pathway was negligible $(0.08 \%)$. The contribution of the deathreceptor pathway was about $29 \%$. Using mitochondrial DNA-depleted $\mathrm{p}^{0}$ cells, Hara et al. [58] demonstrated that mitochondria play a critical role in apoptosis induced by cisplatin and that mitochondrial DNA is a potential target for cisplatin. Also, mitochondria-enriched renal cells in the proximal tubule are critical sites for the occurrence of side effects of cisplatin $[59,60]$. These experimental results suggest that the mitochondrial pathway is the major apoptotic pathway involved in the nephrotoxicity of cisplatin.

The sum of the contributions of all three pathways to the total apoptosis level was about $75 \%$, whereas $25 \%$ of the total apoptosis level was attributable to cross talk among pathways. These results indicated that the level of apoptosis was affected not only by cisplatin concentration, but also by cross talk, i.e., complex interactions of molecular components among pathways.

\section{Conclusions}

Although we applied a systematic analysis of the apoptotic mechanisms induced by cisplatin using a comprehensive model, the approach had several limitations. First, parameter values in the model were based on values obtained from the literature or adjusted manually when sufficient information could not be obtained from the literature or experimental studies. Second, as in previous studies [61,62], we simply set the initial conditions as 0 or 1 . However, as was demonstrated by the

Table 7 Effects of parameters on apoptosis

\begin{tabular}{|c|c|c|c|c|}
\hline \multirow{2}{*}{$\begin{array}{l}\text { Selected parameters } \\
\text { (Higher sensitive parameters } \\
\text { in sensitivity analysis) }\end{array}$} & \multicolumn{2}{|c|}{$+30 \%$ parameter value } & \multicolumn{2}{|c|}{$-30 \%$ parameter value } \\
\hline & $\begin{array}{l}\text { Parameter } \\
\text { range }\end{array}$ & $\begin{array}{c}\text { Apoptosis level } \\
(0.22512)\end{array}$ & $\begin{array}{c}\text { Parameter } \\
\text { range }\end{array}$ & $\begin{array}{c}\text { Apoptosis level } \\
(0.22512)\end{array}$ \\
\hline $\mathrm{k}_{1}^{+}=1 \mu \mathrm{M}^{-1} \mathrm{~s}^{-1}$ & $\mathrm{k}_{1}^{+}=1.3$ & $0.24831(+10.3 \%)$ & $\mathrm{k}_{1}{ }^{+}=0.7$ & $0.19202(-14.7 \%)$ \\
\hline $\mathrm{k}_{13}^{+}=5 \mu \mathrm{M}^{-1} \mathrm{~s}^{-1}$ & $\mathrm{k}_{13}^{+}=6.5$ & $0.19674(-12.6 \%)$ & $\mathrm{k}_{13}^{+}=3.5$ & $0.27136(+20.54 \%)$ \\
\hline $\mathrm{k}_{14}^{+}=0.5 \mu \mathrm{M}^{-1} \mathrm{~s}^{-1}$ & $\mathrm{k}_{14}^{+}=0.65$ & $0.23067(+2.46 \%)$ & $\mathrm{k}_{14}^{+}=0.35$ & $0.2172(-3.52 \%)$ \\
\hline $\mathrm{k}_{15}^{+}=0.5 \mu \mathrm{M}^{-1} \mathrm{~s}^{-1}$ & $\mathrm{k}_{15}^{+}=0.65$ & $0.23067(+2.46 \%)$ & $\mathrm{k}_{15}^{+}=0.35$ & $0.2172(-3.52 \%)$ \\
\hline $\mathrm{k}_{29}^{+}=0.5 \mu \mathrm{M}^{-1} \mathrm{~s}^{-1}$ & $\mathrm{k}_{29}^{+}=0.65$ & $0.22952(+1.95 \%)$ & $\mathrm{k}_{29}^{+}=0.35$ & $0.21911(-2.66 \%)$ \\
\hline $\mathrm{k}_{30}^{+}=0.5 \mu \mathrm{M}^{-1} \mathrm{~s}^{-1}$ & $\mathrm{k}_{30}^{+}=0.65$ & $0.22952(+1.95 \%)$ & $\mathrm{k}_{30}^{+}=0.35$ & $0.21911(-2.66 \%)$ \\
\hline $\mathrm{k}_{31}^{+}=1 \mu \mathrm{M}^{-1} \mathrm{~s}^{-1}$ & $\mathrm{k}_{31}^{+}=1.3$ & $0.22952(+1.95 \%)$ & $\mathrm{k}_{31}^{+}=0.7$ & $0.21911(-2.66 \%)$ \\
\hline $\mathrm{k}_{32}^{+}=0.5 \mu \mathrm{M}^{-1} \mathrm{~s}^{-1}$ & $k_{32}^{+}=0.65$ & $0.23424(+4.05 \%)$ & $\mathrm{k}_{32}^{+}=0.35$ & $0.20999(-6.72 \%)$ \\
\hline $\mathrm{k}_{33}^{+}=1 \mu \mathrm{M}^{-1} \mathrm{~s}^{-1}$ & $\mathrm{k}_{33}^{+}=1.3$ & $0.232(+3.05 \%)$ & $\mathrm{k}_{33}^{+}=0.7$ & $0.21389(-4.98 \%)$ \\
\hline $\mathrm{k}_{34}^{+}=1 \mathrm{~s}^{-1}$ & $\mathrm{k}_{34}^{+}=1.3$ & $0.2392(+6.25 \%)$ & $\mathrm{k}_{34}^{+}=0.7$ & $0.19967(-11.3 \%)$ \\
\hline $\mathrm{k}_{36}^{+}=1 \mathrm{~s}^{-1}$ & $\mathrm{k}_{36}^{+}=1.3$ & $0.238(+5.72 \%)$ & $\mathrm{k}_{36}^{+}=0.7$ & $0.20434(-9.23 \%)$ \\
\hline
\end{tabular}


sensitivity analyses and perturbation test of the parameters and initial conditions (described in the "Methods" section), these limitations were not expected to greatly alter the main findings of this study. In a future study, we will design a smaller model that focuses on the main apoptotic pathway by cisplatin and will obtain parameters by fitting the model to experimental data.

\section{Methods}

\section{Mathematical model}

Mathematical descriptions of interactions of the mechanistic parts of the pathways were modeled based on biochemical reaction equations. The signal transduction network of apoptotic reactions is represented by ordinary differential equations (ODEs). This network leads to a set of 44 ODEs with 24 reaction partners (Table 3 and Table 4). In the reactions, the effects of synthesis and degradation are not taken into account. The differential equations in the modeling of the signaling pathways were solved using MATLAB library functions.

\section{Parameters}

Simulation of a differential equation requires parameters for each step of the biochemical reactions. For our model, parameter values were chosen based on previous experimental reports on various apoptosis pathways [26,63]. For parameters that had not been reported in the literature, we adjusted the values to achieve consistency with other parameters and with output through iterative computations using MATLAB. Table 5 and Table 6 show kinetic parameters of the reactions (reaction rate constants) and the initial conditions of the components. The reaction rates are dependent on these concentrations and on biochemical parameters. However, most of the kinetic parameters and initial concentrations $(t=0)$ are unknown and subject to parameter estimation. To resolve the problem of a large number of unknown parameters, Zhang et al. [61] and other groups [64-66] used dimensionless concentrations for all concentrations. Because we do not have sufficient experimental data and information in the model, we also used dimensionless concentrations and set the initial conditions to 0 or 1 . The pre-expressed components, such as caspase- 3 and cytochrome $c$ in mitochondria (Cyt. $c_{\text {mit }}$ ), were set to 1 , and the post-expressed components by stimulus, such as activated caspase- 3 and leaked cytochrome $c$ in the cytosol (Cyt. $c_{\text {leaked }}$ ), were set to 0 at time 0 . All values are given in arbitrary units, i.e., dimensionless or relative units.

Sensitivity analysis of the model parameters and initial conditions of the model variables were performed using SimBiology in MATLAB. As is shown in Figure 8, sensitivity analysis was carried out with respect to rate constants, initial conditions of model variables, and both rate constants and initial conditions, respectively. Among the rate constants, the parameter $\mathrm{k} 1$ exhibited a relatively high sensitivity (Figure 8A). Sensitivity analysis of initial conditions of the model variables (Figure 8B) showed that the level of apoptosis was more sensitive to the initial conditions in terms of Caspase 8 and IAP (Figure 8B). Figure $8 \mathrm{C}$ shows the sensitivity of each rate constant for the whole model. For rate constants that had relatively high sensitivities, we tested the robustness of the parameters by perturbing the values within $+/-30 \%$. Table 7 shows the results of the perturbation test. In all cases tested, the level of apoptosis changed slightly, within $+/-10 \%$ according to the variation in the chosen parameter, except for parameters, $\mathrm{k} 1$ and $\mathrm{k} 13$, demonstrating the overall robustness of the simulation results with respect to parameter perturbations.

\section{Competing interests}

The authors declared that they have no competing interests.

\section{Authors' contributions}

JYH designed the model and performed the simulations, and wrote the manuscript. GHK and JWK assisted modeling and writing of the manuscript. SSK assisted modeling. ES and KHC helped the simulations and reviewed the manuscript. EBS designed/supervised the work and reviewed the manuscript. All authors read and approved the final manuscript.

\section{Acknowledgments}

This research was support by a grant (10182KFDA992-2102) from the Korea Food \& Drug Administration in 2011 and the Ministry of Education, Science \& Technology (2011-0011762).

\section{Author details}

'Department of Mechanical and Biomedical Engineering, Kangwon National University, 192-1, Hyoja 2-dong, Chuncheon, Gangwon-do 200-701, Republic of Korea. ${ }^{2}$ Department of Medical Biochemistry, Suzuka University of Medical Science, 3500-3 Minamitamagaki, Suzuka mie 513-8670, Japan. ${ }^{3}$ Department of Bio and Brain Engineering, Korea Advanced Institute of Science and Technology (KAIST), 291 Daehak-ro, Yuseong-gu, Daejeon 305-701, Republic of Korea.

Received: 28 March 2012 Accepted: 27 August 2012

Published: 11 September 2012

\section{References}

1. Rose PG, Bundy BN, Watkins EB, Thigpen JT, Deppe G, Maiman MA, Clarke-Pearson DL, Insalaco S: Concurrent cisplatin-based radiotherapy and chemotherapy for locally advanced cervical cancer. N Engl J Med 1999, 340:1144-1153.

2. Vokes EE, Weichselbaum RR, Mick R, McEvilly JM, Haraf DJ, Panje WR: Favorable long-term survival following induction chemotherapy with cisplatin, fluorouracil, and leucovorin and concomitant chemoradiotherapy for locally advanced head and neck cancer. J Natl Cancer Inst 1992, 84:877-882.

3. Pabla N, Dong Z: Cisplatin nephrotoxicity: mechanisms and renoprotective strategies. Kidney Int 2008, 73:994-1007.

4. Chirino Yl, Pedraza-Chaverri J: Role of oxidative and nitrosative stress in cisplatin-induced nephrotoxicity. Exp Toxicol Pathol 2009, 61:223-242

5. Yao X, Panichpisal K, Kurtzman N, Nugent K: Cisplatin nephrotoxicity: a review. Am J Med Sci 2007, 334:115-124.

6. Servais H, Ortiz A, Devuyst O, Denamur S, Tulkens PM, Mingeot-Leclercq MP: Renal cell apoptosis induced by nephrotoxic drugs: cellular and molecular mechanisms and potential approaches to modulation. Apoptosis 2008, 13:11-32.

7. Lieberthal W, Triaca $V$, Levine J: Mechanisms of death induced by cisplatin in proximal tubular epithelial cells: apoptosis vs. necrosis. Am J Physiol 1996, 270:F700-F708. 
8. Servais H, Van Der Smissen P, Thirion G, Van der Essen G, Van Bambeke F, Tulkens PM, Mingeot-Leclercq MP: Gentamicin-induced apoptosis in LLC-PK1 cells: involvement of lysosomes and mitochondria. Toxicol App/ Pharmacol 2005, 206:321-333.

9. Lee RH, Song JM, Park MY, Kang SK, Kim YK, Jung JS: Cisplatin-induced apoptosis by translocation of endogenous Bax in mouse collecting duct cells. Biochem Pharmacol 2001, 62:1013-1023.

10. Raffray M, Cohen GM: Apoptosis and necrosis in toxicology: a continuum or distinct modes of cell death? Pharmacol Ther 1997, 75:153-177.

11. Gordon JA, Gattone VH 2nd: Mitochondrial alterations in cisplatin-induced acute renal failure. Am J Physiol 1986, 250:F991-F998.

12. Mandic A, Hansson J, Linder S, Shoshan MC: Cisplatin induces endoplasmic reticulum stress and nucleus-independent apoptotic signaling. J Biol Chem 2003, 278:9100-9106.

13. Chauhan SS, Liang XJ, Su AW, Pai-Panandiker A, Shen DW, Hanover JA, Gottesman MM: Reduced endocytosis and altered lysosome function in cisplatin-resistant cell lines. Br J Cancer 2003, 88:1327-1334.

14. Brune B: Nitric oxide and apoptosis in mesangial cells. Kidney Int 2002, 61:786-789.

15. Budihardjo I, Oliver H, Lutter M, Luo X, Wang X: Biochemical pathways of caspase activation during apoptosis. Annu Rev Cell Dev Biol 1999, 15:269-290.

16. Li P, Nijhawan D, Budihardjo I, Srinivasula SM, Ahmad M, Alnemri ES, Wang X: Cytochrome $c$ and dATP-dependent formation of Apaf-1/caspase-9 complex initiates an apoptotic protease cascade. Cell 1997, 91:479-489.

17. Chen M, Wang J: Initiator caspases in apoptosis signaling pathways. Apoptosis 2002, 7:313-319.

18. Mayer B, Oberbauer R: Mitochondrial regulation of apoptosis. News Physiol Sci 2003, 18:89-94

19. Fariss MW, Chan CB, Patel M, Van Houten B, Orrenius S: Role of mitochondria in toxic oxidative stress. Mol Interv 2005, 5:94-111.

20. Lavrik IN, Eils R, Fricker N, Pforr C, Krammer PH: Understanding apoptosis by systems biology approaches. Mol Biosyst 2009, 5:1105-1111.

21. Kitamura M: Endoplasmic reticulum stress and unfolded protein response in renal pathophysiology: Janus faces. Am J Physiol Renal Physiol 2008, 295:F323-F334.

22. Inagi R: Endoplasmic reticulum stress in the kidney as a novel mediator of kidney injury. Nephron Exp Nephrol 2009, 112:e1-e9.

23. Fussenegger M, Bailey JE, Varner J: A mathematical model of caspase function in apoptosis. Nat Biotechnol 2000, 18:768-774.

24. Choi HS, Han S, Yokota H, Cho KH: Coupled positive feedbacks provoke slow induction plus fast switching in apoptosis. FEBS Lett 2007, 581:2684-2690.

25. Huber HJ, Rehm M, Plchut M, Dussmann H, Prehn JH: APOPTO-CELL-a simulation tool and interactive database for analyzing cellular susceptibility to apoptosis. Bioinformatics 2007, 23:648-650.

26. Legewie S, Bluthgen $\mathrm{N}$, Herzel $\mathrm{H}$ : Mathematical modeling identifies inhibitors of apoptosis as mediators of positive feedback and bistability PLoS Comput Biol 2006, 2:e120.

27. Jordan P, Carmo-Fonseca M: Molecular mechanisms involved in cisplatin cytotoxicity. Cell Mol Life Sci 2000, 57:1229-1235.

28. Kartalou M, Essigmann JM: Recognition of cisplatin adducts by cellular proteins. Mutat Res 2001, 478:1-21.

29. Tsuruya K, Tokumoto M, Ninomiya T, Hirakawa M, Masutani K, Taniguchi M, Fukuda K, Kanai H, Hirakata H, lida M: Antioxidant ameliorates cisplatininduced renal tubular cell death through inhibition of death receptormediated pathways. Am J Physiol Renal Physiol 2003, 285:F208-F218.

30. Razzaque MS, Koji T, Kumatori A, Taguchi T: Cisplatin-induced apoptosis in human proximal tubular epithelial cells is associated with the activation of the Fas/Fas ligand system. Histochem Cell Biol 1999, 111:359-365.

31. Tsuruya K, Ninomiya T, Tokumoto M, Hirakawa M, Masutani K, Taniguchi M, Fukuda K, Kanai H, Kishihara K, Hirakata H, lida M: Direct involvement of the receptor-mediated apoptotic pathways in cisplatin-induced renal tubular cell death. Kidney Int 2003, 63:72-82.

32. Seth R, Yang C, Kaushal V, Shah SV, Kaushal GP: p53-dependent caspase-2 activation in mitochondrial release of apoptosis-inducing factor and its role in renal tubular epithelial cell injury. J Biol Chem 2005, 280:31230-31239

33. Pabla N, Huang S, Mi QS, Daniel R, Dong Z: ATR-Chk2 signaling in p53 activation and DNA damage response during cisplatin-induced apoptosis. J Biol Chem 2008, 283:6572-6583.
34. Chipuk JE, Kuwana T, Bouchier-Hayes L, Droin NM, Newmeyer DD, Schuler M, Green DR: Direct activation of Bax by p53 mediates mitochondrial membrane permeabilization and apoptosis. Science 2004, 303:1010-1014.

35. Kruidering M, Van de Water B, de Heer E, Mulder GJ, Nagelkerke JF: Cisplatin-induced nephrotoxicity in porcine proximal tubular cells: mitochondrial dysfunction by inhibition of complexes I to IV of the respiratory chain. J Pharmacol Exp Ther 1997, 280:638-649.

36. Nishikawa M, Nagatomi $H$, Nishijima M, Ohira G, Chang BJ, Sato E, Inoue M: Targeting superoxide dismutase to renal proximal tubule cells inhibits nephrotoxicity of cisplatin and increases the survival of cancer-bearing mice. Cancer Lett 2001, 171:133-138.

37. Crompton M: The mitochondrial permeability transition pore and its role in cell death. Biochem J 1999, 341:233-249.

38. Green DR, Reed JC: Mitochondria and apoptosis. Science 1998, 281:1309-1312.

39. Kim JS, He L, Lemasters JJ: Mitochondrial permeability transition: a common pathway to necrosis and apoptosis. Biochem Biophys Res Commun 2003, 304:463-470.

40. Kroemer G, Reed JC: Mitochondrial control of cell death. Nat Med 2000, 6:513-519

41. Mandic A, Viktorsson K, Strandberg L, Heiden T, Hansson J, Linder S, Shoshan MC: Calpain-mediated Bid cleavage and calpain-independent Bak modulation: two separate pathways in cisplatin-induced apoptosis. Mol Cell Biol 2002, 22:3003-3013.

42. Nakagawa T, Yuan J: Cross-talk between two cysteine protease families. Activation of caspase-12 by calpain in apoptosis. J Cell Biol 2000, 150:887-894.

43. Boyce M, Yuan J: Cellular response to endoplasmic reticulum stress: a matter of life or death. Cell Death Differ 2006, 13:363-373.

44. Qian W, Nishikawa M, Haque AM, Hirose M, Masimo M, Sato E, Inoue M: Mitochondrial density determines the cellular sensitivity to cisplatininduced cell death. Am J Physiol 2005, 289:C1466-C1475.

45. Hara K, Kasahara E, Takahashi N, Konishi M, Inoue J, Jikumaru M, Kudo S, Okamura $H$, Sato $E$, Inoue M: Mitochondria determine the efficacy of anticancer agents that interact with DNA but not the cytoskeleton. J Pharmacol Exp Ther 2011, 337:838-845.

46. Wei Q, Dong G, Franklin J, Dong Z: The pathological role of Bax in cisplatin nephrotoxicity. Kidney Int 2007, 72:53-62.

47. Kaushal GP, Kaushal V, Hong X, Shah SV: Role and regulation of activation of caspases in cisplatin-induced injury to renal tubular epithelial cells. Kidney Int 2001, 60:1726-1736.

48. Park MS, De Leon M, Devarajan P: Cisplatin induces apoptosis in LLC-PK1 cells via activation of mitochondrial pathways. J Am Soc Nephrol 2002, 13:858-865.

49. Baek SM, Kwon CH, Kim JH, Woo JS, Jung JS, Kim YK: Differential roles of hydrogen peroxide and hydroxyl radical in cisplatin-induced cell death in renal proximal tubular epithelial cells. J Lab Clin Med 2003, 142:178-186.

50. Susin SA, Lorenzo HK, Zamzami N, Marzo I, Snow BE, Brothers GM, Mangion J, Jacotot E, Costantini P, Loeffler M, Larochette N, Goodlett DR, Aebersold R, Siderovski DP, Penninger JM, Kroemer G: Molecular characterization of mitochondrial apoptosis-inducing factor. Nature 1999, 397:441-446.

51. Daugas E, Nochy D, Ravagnan L, Loeffler M, Susin SA, Zamzami N, Kroemer G: Apoptosis-inducing factor (AIF): a ubiquitous mitochondrial oxidoreductase involved in apoptosis. FEBS Lett 2000, 476:118-123.

52. Nakagawa T, Zhu H, Morishima N, Li E, Xu J, Yankner BA, Yuan J: Caspase12 mediates endoplasmic-reticulum-specific apoptosis and cytotoxicity by amyloid-beta. Nature 2000, 403:98-103.

53. Zong WX, Li C, Hatzivassiliou G, Lindsten T, Yu QC, Yuan J, Thompson CB: Bax and Bak can localize to the endoplasmic reticulum to initiate apoptosis. J Cell Biol 2003, 162:59-69.

54. Orrenius S, Zhivotovsky B, Nicotera P: Regulation of cell death: the calcium-apoptosis link. Nat Rev Mol Cell Biol 2003, 4:552-565.

55. Morishima N, Nakanishi K, Takenouchi H, Shibata T, Yasuhiko Y: An endoplasmic reticulum stress-specific caspase cascade in apoptosis. Cytochrome c-independent activation of caspase-9 by caspase-12. J Biol Chem 2002, 277:34287-34294.

56. Camano S, Lazaro A, Moreno-Gordaliza E, Torres AM, de Lucas C, Humanes B, Lazaro JA, Milagros Gomez-Gomez M, Bosca L, Tejedor A: Cilastatin attenuates cisplatin-induced proximal tubular cell damage. J Pharmacol Exp Ther 2010, 334:419-429.

57. Mukhopadhyay P, Horvath B, Zsengeller Z, Zielonka J, Tanchian G, Holovac E, Kechrid M, Patel V, Stillman IE, Parikh SM, Joseph J, 
Kalyanaraman B, Pacher P: Mitochondrial-targeted antioxidants represent a promising approach for prevention of cisplatin-induced nephropathy. Free Radic Biol Med 2012, 52:497-506.

58. Hara K, Kasahara E, Takahashi N, Konishi M, Inoue J, Jikumaru M, Kubo S, Okamura H, Sato E, Inoue M: Mitochondria determine the efficacy of anticancer agents that interact with DNA but not the cytoskeleton. J Pharmacol Exp Ther 2011, 337:838-845.

59. Chang B, Nishikawa M, Sato E, Utsumi K, Inoue M: L-Carnitine inhibits cisplatin-induced injury of the kidney and small intestine. Arch Biochem Biophys 2002, 405:55-64.

60. Fischer U, Schulze-Osthoff K: New approaches and therapeutics targeting apoptosis in disease. Pharmacol Rev 2005, 57:187-215.

61. Zhang T, Brazhnik P, Tyson JJ: Computational analysis of dynamical responses to the intrinsic pathway of programmed cell death. Biophys $J$ 2009, 97:415-434.

62. Schlatter R, Schmich K, Avalos Vizcarra I, Scheurich P, Sauter T, Borner C, Ederer M, Merfort I, Sawodny O: ON/OFF and beyond-a Boolean model of apoptosis. PLoS Comput Biol 2009, 5:e1000595.

63. Bagci EZ, Vodovotz Y, Billiar TR, Ermentrout GB, Bahar I: Bistability in apoptosis: roles of bax, bcl-2, and mitochondrial permeability transition pores. Biophys J 2006, 90:1546-1559.

64. Toivonen HT, Meinander A, Asaoka T, Westerlund M, Pettersson F, Mikhailov A, Eriksson JE, Saxen H: Modeling reveals that dynamic regulation of c-FLIP levels determines cell-to-cell distribution of CD95-mediated apoptosis. J Biol Chem 2011, 286:18375-18382.

65. Bentele M, Lavrik I, Ulrich M, Stosser S, Heermann DW, Kalthoff H, Krammer PH, Eils R: Mathematical modeling reveals threshold mechanism in CD95-induced apoptosis. J Cell Biol 2004, 166:839-851.

66. Stucki JW, Simon HU: Mathematical modeling of the regulation of caspase-3 activation and degradation. J Theor Biol 2005, 234:123-131.

doi:10.1186/1752-0509-6-122

Cite this article as: Hong et al:: Computational modeling of apoptotic

signaling pathways induced by cisplatin. BMC Systems Biology 2012 6:122.

\section{Submit your next manuscript to BioMed Central and take full advantage of:}

- Convenient online submission

- Thorough peer review

- No space constraints or color figure charges

- Immediate publication on acceptance

- Inclusion in PubMed, CAS, Scopus and Google Scholar

- Research which is freely available for redistribution 